\title{
The Experimental study of the spray distance electrostatic spray
}

\author{
Gu Wanyu ${ }^{1}$, Qiu Baijing ${ }^{1} \&$ Zhu Beifen $^{1}$ \\ ${ }^{1}$ Key Laboratory of Modern Agricultural Equipment and Technology, Ministry of Education and \\ Jiangsu Province, Jiangsu University, Zhenjiang 212013, China
}

Keywords: electrostatic spray; droplets coverage; spray distance; blade specifications

\begin{abstract}
: electrostatic spray relatives to non-electrostatic spray has the outstanding advantage in deposite distribution and canopy penetration aspects, which enables droplet moves to the back side of the blade to form the "surround effect." In order to study the impact of distance that nozzle away from the blade to the spray deposition in electrostatic spraying. paper card method was used in this paper while five kinds of spray distance and three kinds of paper card specifications were set up. The results showes that with the increase of spray distance, the back side average coverage and back and front side coverage ratio are parabolic changes.
\end{abstract}

\section{Introduction}

To improve the efficiency of spraying facilities and reduce pesticide drift is very important to crop chemical control. For these, several studies have been done both domestically and overseas. Qiu baijing using micrograph combining with digital image processing technology to analyzed the spraying deposition of smoke machine, the experiment indicate that with the increasing distance, droplet spraying coverage rose firstly and then declined, but the droplets density was of the opposite trend[1]; Latheef, et al, suggested that improve charge-to-mass $(\mathrm{Q} / \mathrm{M})$ ratio in order to increase deposition of pest control materials to the lower surfaces of cotton leaves where the whiteflies reside [2]; Lü Xiaolan, et al, developed tree canopy and deposition shelf (sparse canopy), According to the experiment, sample height, speed, air- blast velocity and spraying pressure all had significant effect on droplets deposition[3]; Foque, et al, Investigated the impact of changes in spray angle and whether air-assisted nozzle to spray deposition distribution[4].

The electrostatic charged sprays for agriculture application can improve overall distribution and the underside leaf deposition due to "wrap-around" effect, hence reduce spray drift, improve canopy penetration and increase deposition efficiency[5-7]. And due to the non-spacing symmetry of the electrostatic spraying, it is essential to determine operating parameters during the actual spraying. As actual spray conditions were simulated, electrostatic spray droplet coverage was detected in this paper, considering the impact of spray distance and different blade specifications

\section{The device and method for measuring the coverage of charged droplets}

\section{Sampling Method Design}

Since vertical downward spray can better discard the affect of uncharged factors, a droplet collection device for vertical downward spray is presented in this paper.

As was shown in Fig.1, four 1200mm long Iron posts were used to insert the soil like a rectangular array, a rectangular box was formatted at a distance of $500 \mathrm{~mm}$ from the ground with wire around in four iron posts, And in the rectangular box horizontal connected six wire; Sampling paper cards were arranged with the clip horizontal folded on the wire in the form of squares, Spacing of the paper card between the left and right recorded as a, while Front and rear recorded as b; From left to right, front to back, respectively numbered the sample paper card in a matrix form. When spraying vertically downward, nozzle is placed at a distance above the No. 22 paper cards in the middle position. The distance from nozzle to the center position of 22 paper cards recorded as $h$. 


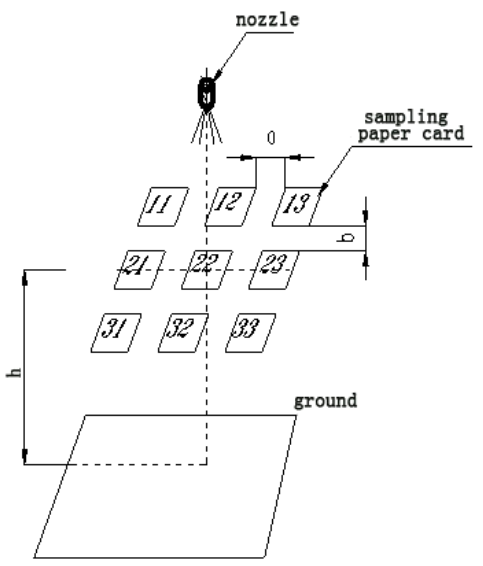

(a) Schematic of the method

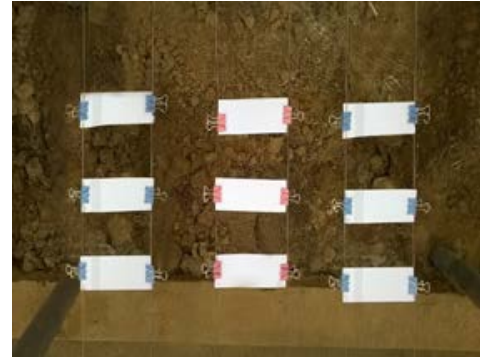

(b) Testing site

Fig.1 Spray Collection method for spray downward vertically

\section{Image reading and processing}

Taking into account long time spray will make the paper cards wet, while short time spray will make the negative coverage poor, so the spray time of test was set to 1s. After spraying, carefully pull the paper card clip on the rope to dry, let it completely dry before bagging grouping. After paper card dry.

After paper card dry, using microscopic image system to read image data. NIKON SMZ100 stereomicroscope and NIS-Elements F5.2 software were used to read the partial image of $10 \mathrm{~mm} \times$ 10mm. the sampling position was shown in Fig.2

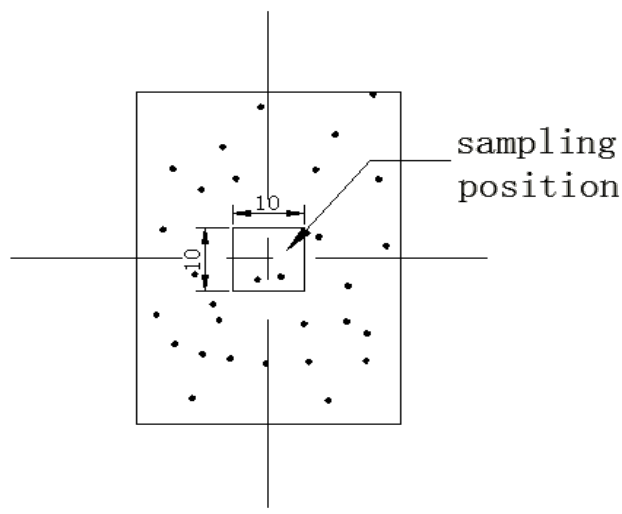

Fig.2 Schematic of sampling position

After reading the image data, use image processing software to get droplet deposition coverage results. The deposition coverage results obtained by color processing, filtering, image binarization, edge detection and other steps.. The Select of threshold value should be adjusted according to different images to ensure the similarity between binarized image and original image.

\section{Experimental Design}

The impact of spray distance to droplet coverage was studied in this paper, which considering the influence of leaf specification. nozzle-to-target distance (h) was used to simulate the spray distance; three paper card specifications were used to simulate the contrast of leaf specification.

Use 3WBJ-16DZ electrostatic sprayer bend nozzle (contactless charge mode, 25kV charging voltage, $0.3 \mathrm{MPa}$ rated working pressure) to spray. Fixed parameters for the experiment: using carmine solution (mass fraction of $0.4 \%$ ) analog pesticides, using $60 \mathrm{~mm} \times 100 \mathrm{~mm}$ as paper card spacing $(\mathrm{a} \times \mathrm{b})$. Variable parameters is shown in Tab. 1 . 
Tab1 variable parameters

\begin{tabular}{cc}
\hline card specifications & nozzle-to-target distance $(\mathrm{mm})$ \\
\hline $148 \mathrm{~mm} \times 105 \mathrm{~mm}(\mathrm{~A} 6)$ & 300 \\
$148 \mathrm{~mm} \times 105 \mathrm{~mm}(\mathrm{~A} 6)$ & 400 \\
$148 \mathrm{~mm} \times 105 \mathrm{~mm}(\mathrm{~A} 6)$ & 500 \\
$148 \mathrm{~mm} \times 105 \mathrm{~mm}(\mathrm{~A} 6)$ & 750 \\
$148 \mathrm{~mm} \times 105 \mathrm{~mm}(\mathrm{~A} 6)$ & 1000 \\
$105 \mathrm{~mm} \times 74 \mathrm{~mm}(\mathrm{~A} 7)$ & 300 \\
$105 \mathrm{~mm} \times 74 \mathrm{~mm}(\mathrm{~A} 7)$ & 400 \\
$105 \mathrm{~mm} \times 74 \mathrm{~mm}(\mathrm{~A} 7)$ & 500 \\
$105 \mathrm{~mm} \times 74 \mathrm{~mm}(\mathrm{~A} 7)$ & 750 \\
$105 \mathrm{~mm} \times 74 \mathrm{~mm}(\mathrm{~A} 7)$ & 1000 \\
$40 \times 100 \mathrm{~mm}$ & 300 \\
$40 \times 100 \mathrm{~mm}$ & 400 \\
$40 \times 100 \mathrm{~mm}$ & 500 \\
$40 \times 100 \mathrm{~mm}$ & 750 \\
$40 \times 100 \mathrm{~mm}$ & 1000 \\
\hline
\end{tabular}

\section{Results and discussion}

three sizes of sample paper cards(A6, A7, $40 \times 100 \mathrm{~mm}$ ) were respectively used to spray under five nozzle-to-target distance $(300 \mathrm{~mm}, 400 \mathrm{~mm}, 500 \mathrm{~mm}, 750 \mathrm{~mm}, 1000 \mathrm{~mm})$ to obtain positive and negative target (sample paper card) droplets coverage. The results was shown in Table 2.

Tab.2 coverage of the front and back of different specification cards about in different nozzle-to-target distance

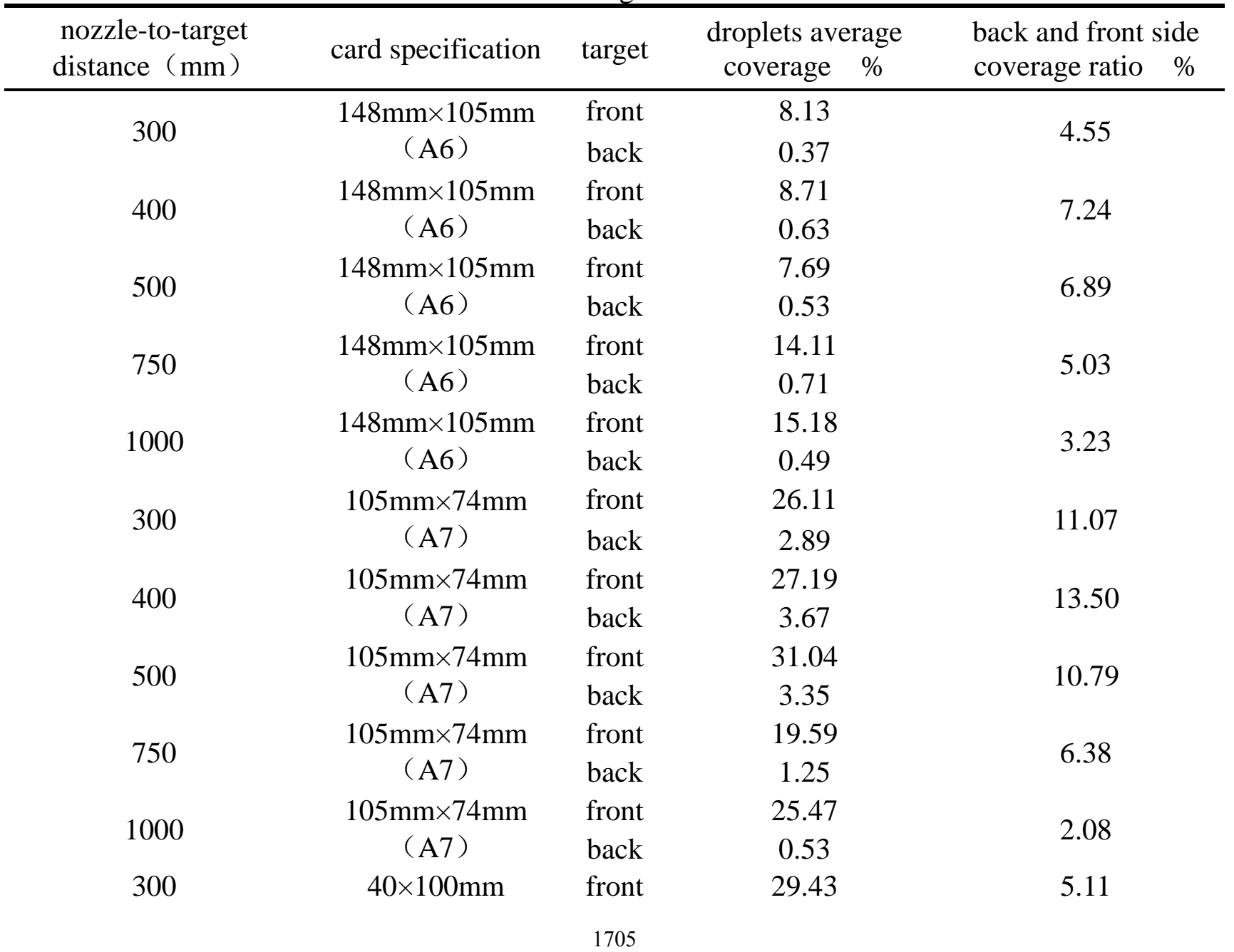




\begin{tabular}{|c|c|c|c|c|}
\hline \multirow{3}{*}{400} & & back & 1.51 & \multirow{3}{*}{9.30} \\
\hline & $40 \times 100 \mathrm{~mm}$ & front & 22 & \\
\hline & $40 \times 100 \mathrm{~mm}$ & back & 2.8 & \\
\hline \multirow{2}{*}{500} & $40 \times 100 \mathrm{~mm}$ & front & 30.97 & \multirow{2}{*}{9.71} \\
\hline & & back & 3.01 & \\
\hline \multirow{2}{*}{750} & $40 \times 100 \mathrm{~mm}$ & front & 23.81 & \multirow{2}{*}{4.87} \\
\hline & & back & 1.16 & \\
\hline \multirow{2}{*}{1000} & $40 \times 100 \mathrm{~mm}$ & front & 16.97 & \multirow{2}{*}{2.05} \\
\hline & $40 \times 10011111$ & back & 0.35 & \\
\hline
\end{tabular}

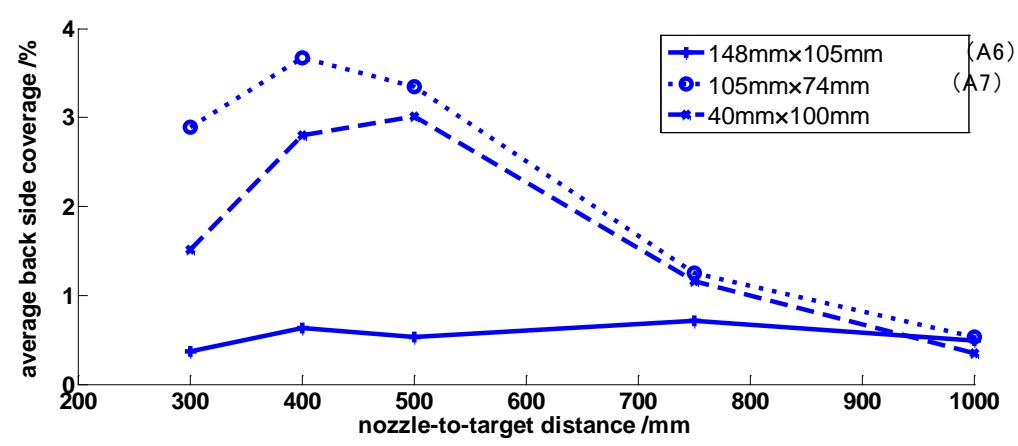

(a) Relationships between card size and average back side coverage in different nozzle-to-target distance

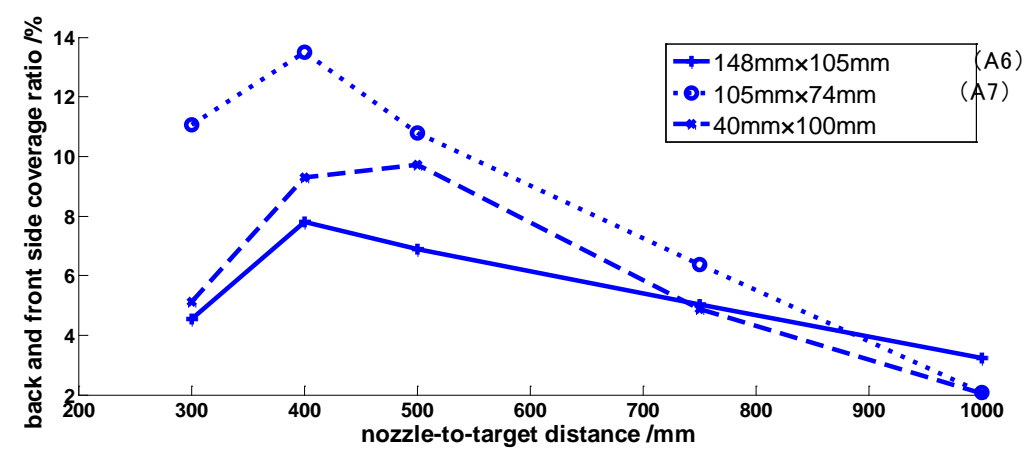

(b) Relationships between card size and back and front side coverage ratio in different nozzle-to-target distance

Fig.3 Relationships between card size and droplets coverage in different nozzle-to-target distance

Combined with three paper card specification Tab. 2 and Fig.3, with the increasing of nozzle-to-target distance, the back side average coverage and back and front side coverage ratio of paper card are all increased first and then decreased, showing parabola, but the highest point of the parabola of this three paper cards are not the same.

Compared with different specifications of paper cards, the back side average coverage and back and front side coverage ratio of paper card are different, and with with the increasing of nozzle-to-target distance, the difference become smaller. And for a smaller paper card, the effect of nozzle-to-target distance changes to the back side average coverage and back and front side coverage ratio are less.

\section{Conclusion}

(1) the coverage experimental methods developed in this paper can detect the electrostatic spray droplet coverage.

(2) with the increase of spray distance, the back side average coverage and back and front side coverage ratio are parabolic changes. There is an optimal spray distance exist. The number of best 
spray distance are associated with the blade specifications (size, shape).

(3) A smaller blade card compared a bigger blade, the effect of spray distance to droplets coverage are less.

\section{Acknowledgements}

The research work was supported by The Project of National Natural Science Funds under Grant No. 31271620, Special Fund for Agro-scientific Research in the Public Interest under Grant No. 201203025-04, Agriculture Science Technology Achievement Transformation Fund under Grant No. 201203025-04, Jiangsu Sci-Tech Support Plan for Agriculture under Grant No. BE2014374 and Jiangsu Sci-Tech Support Plan for Industry under Grant No. BE2014510.

\section{References}

[1] Qiu Baijing, Sha Junyan, Tang Bomin, et al. Analysis of droplets deposition parameters based on micrograph in airtight space[J]. Transactions of the Chinese Society for Agricultural Machinery, 2008, 39(2):55-58.

[2] Latheef M A, Carlton J B, Kirk I W, et al. Aerial electrostatic-charged sprays for deposition and efficacy against sweet potato whitefly (Bemisia tabaci) on cotton[J]. Pest Management Science, 2009, 65(7): 744-752.

[3] Lü Xiaolan, Fu Ximin, Wu Pin, et al. Influence of spray operating parameters on droplet deposition[J]. Transactions of the Chinese Society for Agricultural Machinery, 2011, 42(6):70-75.

[4] Foque D, Nuyttens D, et al. Effect of Air Support and Spray Angle on Coarse Droplet Sprays in Ivy Pot Plants. Transactions of the ASABE, 2011, 54:8.

[5] Maski D, Durairaj D. Effects of charging voltage, application speed, target height, and orientation upon charged spray deposition on leaf abaxial and adaxial surfaces[J]. Crop Protection, 2010, 29(2): 134-141.

[6] Law S E, Steven C C. Depositional Characteristics of Charged and Uncharged Droplets Applied by an Orchard Air Carrier Sprayer[J]. Transactions of the ASAE, 1988, 31(4): 984-989.

[7] Latheef M A, Carlton J B, Kirk I W, et al. Aerial electrostatic-charged sprays for deposition and efficacy against sweet potato whitefly (Bemisia tabaci) on cotton[J]. Pest Management Science, 2009, 65(7): 744-752. 